\title{
Problem-Based Learning in Reflective Pedagogy Paradigm: Innovative Learning in Pharmaceutical Care
}

\author{
Hartayu T S, Wijoyo J, Donowati M W* \\ Faculty of Pharmacy, Sanata Dharma University, Yogyakarta, INDONESIA.
}

\begin{abstract}
Objective: Problem based learning method is one of the learning process in practicing pharmaceutical care in Indonesia. On the other hand, the effective strategy in learning process and character building is reflective pedagogy paradigm. The innovation was done as a new learning process by infusing problem based learning to the reflective pedagogy paradigm. This study was aimed to develop training material to conduct the new learning process. Method: It was started by developing training material, i.e. initiating trigger case in pharmacy management and pharmaceutical care, semester lesson plan, and instrument assessment, based on the Indonesian Pharmaceutical care Standard according to the regulation of the Indonesian Minister of Health no. 73/2016. The training material was then tested to assess its feasibility in the community pharmacy in 3 cities, i.e. Yogyakarta, Solo and Semarang city for a period of one month. Data analysis was done by assessing in the learning process using enumerate methods. Result: Based on the supervisors' and students' reflection, the initiating trigger case is suitable with the daily activities of pharmaceutical
\end{abstract}

care in the community pharmacy, lead them to improve their ability in problem solving, more confident in decision making process, and easier in networking with other health care profession. It indicates that the learning process is feasible to be used, however in part of pharmacy management, it was identified as complicated. Conclusion: The initiating trigger case needs to be revised and retested before it is implemented.

Key words: Community pharmacy, Learning process, Pharmaceutical care, Problem-based learning, Reflective pedagogy paradigm.

Correspondence

Titien Siwi Hartayu, Faculty of Pharmacy, Sanata Dharma University, Yogyakarta, INDONESIA.

Phone: +6281392379595

Email: titien@usd.ac.id; titien_hartayu@yahoo.com

DOI: 10.5530/jyp.2018.2s.1

\section{INTRODUCTION}

Community Pharmacy is one of the place where pharmacist should provide pharmaceutical-care, such as patient education and home pharmacy care for the patients with chronic disease. ${ }^{1}$ Pharmacists should have a good knowledge, attitude and practice, and also skill in patient's education. ${ }^{2-3}$ Unfortunately, most of the customers stated that they do not satisfied regarding with information and consultation about medicines that they have received. ${ }^{4-5}$ Moreover, pharmacists are lack of communication skill ${ }^{6}$ and participation in the rational use of medicines program, ${ }^{7-8}$ and home pharmacy care has not been optimally being practiced yet. ${ }^{3,9}$ Therefore, improving of pharmaceutical-care performance is needed. One of the strategies in improving pharmaceutical-care performance is enhancing managerial and clinical competence of pharmacist during internship by innovating the learning process.

Learning process in practicing pharmaceutical-care in Indonesia use Problem-based Learning (PBL) methods. However, one of the effective strategies in learning process and character building is reflective pedagogy paradigm (RPP), ${ }^{10}$ that is a paradigm and the way of improving quality of personality and character building such as humanity, compassion and responsible person. RPP can be conducted by giving experiences in humanity, continued by experience reflection. Based on the experience reflection, students are facilitated by some action questions, i.e. what intention do they have regarding with their experience? And what will they do to fulfill their intention? and results of the action was then be evaluated. The cycle of RPP is context-experience-reflection-actionevaluation. ${ }^{11-13}$ RPP is applicable in the university learning process, ${ }^{14-15}$ increasing the ability of students' reflection, ${ }^{16-20}$ as a model of learning process which lead to increase the ability to integrate of competence, conscience and compassion in nurse ${ }^{21}$ and also to improve the under- standing and skill of communication about Pharmacotherapy of Pharmacist. ${ }^{10}$

Based on the learning process in practicing pharmaceutical-care in Indonesia use PBL and RPP is useful in improving quality of learning process in some areas, therefore innovation was done by infusing PBL to the RPP. The innovation of the learning process leads to the ability of pharmacist candidates in understanding both the theory and performing in pharmaceutical-care. Those performance is strengthened by the comprehension reflection of their experience, and result in the ability to integrate the competence, conscience and compassion. Indeed, training material is needed to create the innovation. The study is aimed to develop training material to perform pharmaceutical-care using PBL in RPP method.

\section{MATERIALS AND METHODS}

The study is conducted in 2 stages, i.e. the first stage is conducted using qualitative study through focus group discussion among lecturer of pharmacist candidates and then it is continued by panel experts (supervisors: community pharmacists), to develop training-material, i.e., the initiating trigger case, the study semester plan, and the assessment instrument. Steps of the first stage study can be described as follows:

\section{Developing the initiating-trigger case}

Developing draft of the initiating trigger case was conducted by literature review regarding with the standard of Indonesian pharmaceutical care in the community pharmacy, ${ }^{1}$ the expanding role of pharmacist and needs assessment of customer regarding with pharmaceutical care. The initiating trigger case draft was then discussed by the researcher, lecturers, and 
community pharmacists who will be the supervisor for students in practicing pharmaceutical care. The discussion was conducted in the form of Focus Group Discussion (FGD). Based on the FGD's result, the draft was then revised to be more simple and applicable. Before the initiating trigger case was implemented, it was distributed to 5 students to conduct language comprehension test.

\section{Developing study semester plan}

Developing study semester plan was conducted based on the cycle of reflective pedagogy paradigm, i.e. context-experience-reflection-actionevaluation. Context is fulfill by using the final draft of the initiating trigger case. Experience was fulfilled by using problem based learning methods, i.e. providing guideline to construct pharmacist's knowledge and to develop the problem solution. Reflection was fulfilled by using Wijoyo's reflection list. Business plan as an action in pharmacist's managerial role, and home pharmacy care plan as an action in pharmacist's clinical role. The evaluation was conducted by assessing the documentation, including the assessment instrument of the learning process, business plan, and home pharmacy care plan.

\section{Developing assessment instrument}

The assessment instrument was developed based on the important steps in the learning process and the competence which have to be achieved. The assessment instrument was then tested by peer simulation. Results of the test were used to revise the assessment instrument.

\section{Study semester plan}

Internship in the community pharmacy, contributes to the pharmacy management and pharmaceutical care study outcomes. After practice in the community pharmacy, the students should be able to perform pharmaceutical care as a pharmacist. The steps of the problem based learning in reflective pedagogy paradigm process are: 1 . Identify the problems based on the initiating trigger case; 2 . Developing hypothesis; 3 . What data do they need; 4 . What data have they known; 5 . Look for other data that is needed; 6 . Learn what have been known; 7. Active self-learning; 8. Sharing and pooling; 9. Evaluating. After finishing the 9 steps above, both the students and the supervisors fill up the reflection form. In the learning process, students, lecturers, and the supervisors have their own role. Students role are: directing, explaining, asking, criticizer, wrap up, and taking a note. On the other hand, lecturer role are: act as a facilitator, as a model how to conduct the effective study, give direction and feedback, while the community pharmacists act as the field supervisor. During 2 months practice in the community pharmacy, the students have achieved the study outcomes in the first month. The outcomes are: Week 1. The ability of proposing business plan; week 2 . The ability of evaluating medicines cycle management; week 3 . The ability of dispensing including educating patient in rational use of medicines; week 4 . The ability of proposing home pharmacy care plan. The second month is designed to evaluate their achievement. The evaluation is conducted as follows: Week 5. Mini seminar to present about business plan; Week 6. Mini seminar: Presentation about inventory control (part of medicines cycle management); Week 7. Mini seminar: Presentation about dispensing; and Week 8. Mini seminar: Presentation about home pharmacy care plan.

\section{Students Reflection}

The Instructs to lead the students reflections are:

1. List of your experience in the learning process regarding with the material, the process it-self; the goal and the relevance to your profession; 2. What knowledge have you gotten after you try the learning process which is useful for your profession; 3. In your opinion, is the learning process lead you to find the value of life? List it!; 4. List your action plan based on the result of your learning process.

\section{Assessment Instrument}

There were 4 point questions to assess the activities of the pharmacist candidates during they practice in the community pharmacy, i.e.

1. Identifying data and some information; 2. Problems analysis and interpretation; 3. Solution set up and documenting; 4. Monitoring and evaluating. The assessment criteria based on the ability of 1 . Describing the problems; 2 . Appropriateness and systematically analysis; 3 . Thorough analysis; 4. Material selection; 5. Effectiveness communication and teamwork; 6 . On time assignment submission. The grade is divided by 4 categories, i.e.: excellent (> 79), good (69-78), average (56 - 68) and poor $(<56)$. The highest contribution to the final grade is the content of the paper assignment (60\%), the ability of presenting score is $20 \%$, administrative and time submission is $10 \%$ each.

The Initiating-trigger case

Business plan scenario

Pharmacists want to run business in 2 community pharmacies. There are 2 senior pharmacists practice around the location (as competitor). Recommendation permission is not done. Display lay out is well designed with interesting company image. He plans cooperation with practicing physician in his pharmacy.

\section{Evaluation of the quality medicines management (inventory control) scenario}

Healthy pharmacy, is a community pharmacy in Yogyakarta city. The pharmacy provides some medicines based on the Pareto analysis. There is a higher demand on some medicines in this month, that lead to the stock out of some medicines. Therefore, the pharmacy has to buy some medicines from other pharmacy and using "Just in time" methods.

In this case the supervisors should teach the pharmacy graduates about the Pareto analysis, how to solve the stock out, and "Just in time" methods usage. They should think about the competitor of other Pharmacy and also the new regulation regarding with the health insurance.

\section{Dispensing case Scenario}

The prescription that should be analyzed was provided by the community pharmacy where the students practice to perform pharmaceutical care. The students identified the prescription's problems: Are there any administrative, pharmaceutical or clinical problem. They found out that the patient did not have enough money to purchase the prescription. What should Pharmacist do to dispense the prescription?

\section{Home pharmacy care plan}

The mother enter into the 'Healthy Pharmacy' with the prescription contains of Amaryl $^{\circledR} 2 \mathrm{mg}$ (1 tablet before breakfast), Glucophage ${ }^{\circ}$ ( 1 tablet twice a day) and Neurodex ${ }^{\circledast}(1$ tablet twice a day). The patient un-adhered towards the treatment program. The physician did not explain about the medicines. Propose the home pharmacy care plan!

\section{Data collection}

The training material was tested in the community pharmacy in 3 cities, that is, Yogyakarta, Solo and Semarang. Data collection was started on the week 4 and 6 during learning process in practicing pharmaceutical care in the community pharmacy, i.e. documentation of, business plan (week 4) and home pharmacy care plan (week 6). Business plan was the plan of running business in the community pharmacy. On the week 7 and 8 , students present their work, both the business plan and the home pharmacy care plan. The lecturer and the community pharmacists act as the assessor.

\section{Data analysis}

Data analysis was conducted by assessing the paper of business plan and home pharmacy care plan. It was conducted by the lecturer and 
the community pharmacists as the supervisor. The reflection-journal was assessed by the researcher. Both data analyses use the assessment instrument. Results of the study was expected to obtain the initiating trigger case, study semester plan and assessment instrument that have been tested and ready to be used as the training-material in practicing pharmaceutical care in the community pharmacy.

\section{Ethical clearance}

Ethical clearance of the study is stated by the certificate no. 454/C.16/ FK/2017 of the Ethic Committee of the Faculty of Medicines Duta Wacana Christian University, Yogyakarta, Indonesia.

\section{RESULTS}

\section{Training-material language test results}

Result of the language test shows that most of the respondents do not understand about the words of "company image" and "inventory control". This result shows in the Table 1 below:

After the words of "company image" and "inventory control" were changed by other words that more popular and understandable by students, the Initiating Trigger Case were then tested in the Community Pharmacies. The tested are described in 4 parts, i.e.: Results of the tested regarding with The Proposing of Business Plan, Inventory Control, Pharmaceutical Performance, and Home Pharmacy Care. Results of the study show that almost all of students in 3 cities have a good understanding only in knowledge. However, in practice they have not been able to construct a proposal of the business plan properly, they stated that the failed was due to the time constraint in preparing data that were needed. The data that had not been identified were the number of the population that lead to the uncertain estimation of future customers. They could not identified the strength of the business plan, such as how many general physician and specialist around the location, and also the possibility of the threatened for the advance business such as how many community pharmacy around the location. Therefore, revising of the instructions to propose the business plan and adding the time to propose is needed.

In summary, the result is shown in the Table 2 as follows:
Regarding with the home pharmacy care plan, most of the students have a good knowledge, and succeed in constructing home pharmacy care plan. There was only students in one of the community pharmacy in Yogyakarta city was identified that they use complicated case with more than 3 item medicines and inapplicable. In consequently, there were too many drug related problems should be analyzed. On the other hand there was a time constraint to conduct the activity. The initiating trigger case was then modified by selecting patient with the simple case and use less medicines. The newest Initiating trigger case, is shown as follow:

"A young woman approached the prescription counter to have her prescription for 15 nystatin vaginal tablets. Based on the results of the screening prescription, there are some Drug Related Problems (DRP). She does not have enough money to pay the medicine. How do you serve the patient?"

\section{Result of the Students Performance Assessment Through the presentation, discussion and the paper}

By using the newest Initiating Trigger Case, Students' performance were then assessed by the Preceptor and the Lecturer towards Students' work through the Mini Seminar and the Paper work. Result of the study show that the students in Yogyakarta City have achieved the excellent mark for the Inventory Control, Pharmaceutical Performance and Home Pharmacy Care, and good in the feasibility Study. The students in Semarang achieved excellent in all of subjects, Feasibility study, Inventory Control, Pharmaceutical Care Performance and Home Pharmacy Care. Students in Solo City achieved the excellent mark in the Feasibility Study and Home Pharmacy Care, and Good in Inventory Control and Pharmaceutical Care Performance. In summary, the Results is shown in the Table 3, as follows:

\section{Supervisors' Reflection}

The supervisors in Yogyakarta City stated that the initiating trigger case is suitable with the daily activities of pharmaceutical care in the community pharmacy. All of the supervisors in Yogyakarta, Solo and Semarang city were pleased with the initiating trigger case, because it makes them easier in supervising the Students. However, the supervisors

Table 1: Language Test Result.

\begin{tabular}{ccccc}
\hline Number of Respondents & Initiating Trigger Case 1 & Initiating Trigger Case 2 & Initiating Trigger Case 3 & Initiating Trigger Case 4 \\
\hline R-1 & Understandable & Inventory control? & Understandable & Understandable \\
R-2 & Company image? & understandable & understandable & understandable \\
R-3 & Company image? & understandable & understandable & understandable \\
R-4 & Company image? & Inventory control? & understandable & understandable \\
R-5 & Company image? & understandable & understandable & understandable \\
\hline
\end{tabular}

Table 2: Feedback by the Preceptor about the Initiating Trigger Case.

\begin{tabular}{|c|c|c|}
\hline No. & Activity & Feedback by the Preceptors of the Community Pharmacies \\
\hline 1. & Proposing Business Plan & $\begin{array}{l}\text { 1. The Initiating Trigger Case is understandable and easy to be implemented. } \\
\text { 2. It needs to make clearer about the framework. } \\
\text { 3. Students have a good knowledge in the feasibility study, however have not a good enough in analytical } \\
\text { part. }\end{array}$ \\
\hline 2. & Inventory Control & The Initiating Trigger Case is understandable and easy to be implemented \\
\hline 3. & Pharmaceutical Care Performance & $\begin{array}{l}\text { The Initiating Trigger Case is understandable, however it needs to modified based on the real prescription in the } \\
\text { Community Pharmacy. }\end{array}$ \\
\hline 4. & Home Pharmacy Care & $\begin{array}{l}\text { 1. The Initiating Trigger Case has been modified by the Preceptor based on the real problem in the } \\
\text { Community Pharmacy. }\end{array}$ \\
\hline & & 2. Students have a good knowledge and experience in performing the Home Pharmacy Care. \\
\hline
\end{tabular}


Table 3: The Grade of the Students' Performance Assessment.

\begin{tabular}{ccccc}
\hline No The Initiating Trigger Case & Topic & Yogyakarta City & Semarang City & Solo City \\
\hline & & \multicolumn{3}{c}{ Preceptor/ Lecturer } \\
1 & Feasibility Study & $72 / 70$ & $80 / 77$ & $76 / 80$ \\
2 & Inventory Control & $76 / 76$ & $78 / 78$ & $75 / 78$ \\
3 & Pharmaceutical Care & $80 / 78$ & $78 / 77$ & $74 / 78$ \\
4 & Home Pharmacy Care & $80 / 84$ & $78 / 82$ & $80 / 80$ \\
\hline
\end{tabular}

*>75: Excellent; 70 - 75: good; $<70$ average

in Semarang city stated that they still need standard operational procedure in the learning process.

\section{Students' Reflection}

Result of the study shows that most of the students stated that by using initiating trigger case, they have gotten an experience of how to identify and solve the problems that lead them to improve their ability in problem solving, more confident in decision making process, easier in networking with other health care profession. In other words, the learning process is relevant with the role of Pharmacist because it makes them easier to reach the study goal in practicing pharmaceutical care.

\section{DISCUSSION}

Many study about the implementation of reflective pedagogy paradigm has been done, among others are: Steps in reflective pedagogy paradigm based on active learning and reflection on experience; ${ }^{13-15}$ Implementation of reflection result in improving the ability of the students in critical thinking; ${ }^{10,17}$ Helps students to be responsible in the learning process and decision making process; ${ }^{16}$ Reflective pedagogy paradigm can also improve the ability of students in reflecting, involving in the learning process, understanding about the important of the material training, confident, critical thinking, and can be a model as a method to integrate the competence, conscience and compassion ${ }^{21}$ of the students;

Results of the study show that after conducting problem based learning using the steps of the reflective pedagogy paradigm which was based on active learning and reflection on experience, ${ }^{13-15}$ almost all of the students have a good knowledge about the business plan, pharmaceutical care in analyzing of the prescription, drug related problems and how to solve it, and how to propose home pharmacy care plan. Unfortunately, the improving of the knowledge is not followed by the improving of the ability in practicing of the constructing the business plan and the home pharmacy care plan. Based on the results of the discussion in the Mini Seminar among the researcher, lecturer, supervisors and students in the week 7 and week 8 , the underlying factors of the failed of practicing to construct the business plan are 1 . The time constraint to collect the data that was needed in proposing the action plan, i.e. business and home pharmacy care plan, and 2. The unclear of the Initiating trigger case. Therefore, the Initiating trigger case were then revised to make clearer that would lead to manage the availability of the time. After the initiating trigger case was revised, the students succeed in constructing business and home pharmacy care plan. These results are showed through the achievement of the grade of the students' performance assessment and the reflection of experience of the students that stated that they are pleased with the Initiating trigger case that gave them a good experience to solve any problem in conducting pharmaceutical care in the community pharmacy. The experience make them more confident in the decision process because they have more chance to ask many questions regarding with the data that they are needed. Therefore, they can have a complete data to propose the business plan. These results are supported by other study that stated by implementation of reflection experience result in improving the ability of the students in critical thinking. ${ }^{10,17}$ The students are pleased with the Initiating trigger case, indicates that the Initiating trigger case is effective and suitable to be used in the learning process. Moreover, by using reflective pedagogy paradigm, students are able to perform some action to implement their pharmaceutical care knowledge in the real life which is showed by their reflection and action plan. These results is supported by other study that reflective pedagogy paradigm is claimed as a way to build the strong character as competence, conscience, and compassion. ${ }^{21}$ Competence are showed by the ability of proposing business plan and home pharmacy care plan and also in doing the dispensing case especially in analyzing of the prescriptions and drug related problems. Conscience and compassion are showed by the ability in caring for the patients especially in explaining the used of medicines to the patient with patience and confidence. The students claimed that the Initiating trigger case improved their ability in the problem solving and makes them more confident in the decision making process and in communicate with either patients, medical doctor or other health provider. This claimed is supported by the achievement of the excellent grade of the students' performance. These results indicate that the Initiating trigger case is as effective as education program based on other studies which is stated that the problem based learning can improve problem solving, critical and rational thinking in clinical problem, and also as students' self-direct learning. ${ }^{16,22-25}$

\section{CONCLUSION}

Training materials to perform pharmaceutical care practice are Initiating Trigger Case, Semester Study Plan, and Assessment Instrument, were developed based on the simplest real case in each community pharmacy, can be used as a guideline for the Preceptors and the Students to perform Pharmaceutical Care in the Community Pharmacy. This method can be a model to improve learning process and critical thinking of lecturer, and after re-tested, it will be ready to disseminate to be used by students throughout Indonesia.

\section{ACKNOWLEDGEMENT}

Special thanks to the Ministry of Research, Technology and Higher Education of The Republic of Indonesia for the financial support as outlined in the contract agreement No. 051/HB-LIT/IV/2017, on the $14^{\text {th }}$ April 2017, which made this study is possible. Special thanks to the director of PT Kimia Farma for the chance, the Kimia Farma's Pharmacists for their contribution as the supervisors, and to the students of Pharmacy Profession Program batch 34 Faculty Pharmacy Sanata Dharma University for their contribution as in the study.

\section{CONFLICT OF INTEREST}

The authors declare no conflict of interest.

\section{ABBREVIATIONS}

PBL: Problem Based Learning; RPP: Reflective Pedagogy Paradigm. 


\section{SUMMARY}

Problem-based learning method is a learning process practiced in Pharmaceutical-care in Indonesia. On the other hand, reflective pedagogy paradigm is recognized as effective strategy in learning process, character building, and improving the quality of personality such as humanity, compassion and responsible person. Reflective pedagogy paradigm can be performed by giving experiences in humanity, continued by experience reflection. The experience-reflection leads to the action, and finally evaluation of the results of action. Reflective pedagogy paradigm can be summarized as follows: Context-experience-reflection-action-evaluation. The context is according to the regulation of The Indonesian Minister of Health No. 73/ 2016. The educational material were developed based on the Standard of Indonesian Pharmacist Competencies, has been tested in 9 Community Pharmacies in 3 Cities, results in improving the ability of the students in problem solving with more confidence in decision making process, and easier in teamwork building with other health-care professionals. The most important factor which support the success of the learning process is the educational material i.e. Initiating Trigger-case, which was developed based on the simplest real problem in each Community Pharmacy, and let the students improve it in the future activities. The real problem in each Community Pharmacy can be obtained through Focus Group Discussions among the preceptors as future supervisors.

In summary of the study, by developing educational material to perform pharmaceutical-care practice, i.e. Initiating-trigger case, semester study plan, and assessment instrument can be used by students and the supervisors as a guideline and make them easier to perform Pharmaceuticalcare in the Community Pharmacy. In addition, this method can be a model to improve learning process in the future by utilizing students' reflection list and improving the creativity of learning process, educational material design, and critical thinking of the lecturer.

\section{REFERENCES}

1. Department of Health. Minister of health regulation no. 1027/MOH/SK/IX/2004, the standard of pharmaceutical Care In The Community Pharmacy in Indonesia. 2004. Available from : http://hukor.kemkes.go.id/hukor/kepmenkes/2004

2. Aurelia E. Expectations and beliefs of pharmacy customers on the role of pharmacists in west Surabaya. Calyptra. 2013;2(1).

3. Hartayu TS, Widayati A, Wijoyo Y. Improving drug information service for diabetic patients. IJCP. 2013;2(3)

4. Sari IP. Customers motivation towards drug information and consultation in the community pharmacy in Yogyakarta city. Indonesian Pharmacy Magazine. $2001 ; 12(2) 79-83$

5. Anggraeni EA, Nita Y, Soemiati. Community pharmacy's performance and the self-medication's customers expectations towards pharmaceutical care service in Gresik city. Airlangga Pharmacy Magazine. 2009;7(2).
6. Handayani RS, Gitawati R, Muktiningsih SR, Raharni. Needs assessment of pharmacy customers expectations toward drug information service and pharmacists readiness in giving information regarding with the drug for degenerative and chronic disease. Pharmaceutical Science Magazine. 2006;3(1):38-46.

7. Herman MJ, Supardi S, Susanti R, Isnawati A, Muktiningsih SR, Apriany P. The underlying factors of prescription service by pharmacist assisstant in the community pharmacy. Health Research Bulletin. 2004;32(3):119-26.

8. Purwanti A, Harianto, Supardi S. The implementation of the standard of pharmaceutical care service in the community pharmacy in Jakarta in 2003. Pharmaceutical Science Magazine. 2004;1(2):102-16.

9. Setiawan D, Hasanmihardja M, Mahatir A, The influences of the pharmaceutical care service toward pharmacy customers satisfaction in the community pharmacy in Tegal District. Jurnal Farmasi Indonesia. 2010;5(2):100-8.

10. Wijoyo Y, Rahayu GR, Dwiprahasto I. Evaluation on pharmacotherapy learning strategies based on reflective pedagogy paradigm in pharmacists education program Sanata Dharma University. IJPCR. 2016;8(5):493-9.

11. Jesuit Secondary Education Association (JSEA). Ignatian Pedagogy Practical Approach. Originally published as a monograph: Reprinted as Appendix B in The Jesuit Ratio Studiorum of 1599: 400 th Anniversary Perspectives. 1993.

12. Mann K, Gordon J, MacLeod A. Reflections and reflective practice in health professions education: A systematic review. Adv in Health Sci Educ. 2009;14(4):595-621. Available from : doi : 10.1007/s10459-007-9090-2

13. Van Hise J, Massey DW. Applying the ignatian pedagogical paradigm to the creation of an accounting ethics course. J Bus Ethics. 2010;96(3):453-65

14. Hayes CX. Paradoxes, parallels and pedagogy: A case study of ignatian pedagogy and of teachers' perception of its implementation in Australian Jesuit Schools. Dissertation, Australian Catholic University, Victoria. 2006.

15. Defeo JA. Old wine in new skin : Ignatian pedagogy, compatible with and contributing to jesuit higher education. Dissertation, Fordham University. 2009

16. Crable $\mathrm{E}$, Brodzinski J. Designing online business courses using the ignatian pedagogical paradigm. Unpublished research, Xavier University. 2010.

17. Mc Avoy M, Crowe T, Lotz R, Truka B. The influence of the ignatian pedagogical paradigm on instructors integrating it into undergraduate courses in the college of professional studies at Marquette University. Jesuit Higher Education. 2012;1(2):82-105

18. Van Hise. Transformative education - using ignatian pedagogy to teach business ethics. Fairfield University. 2012

19. Wallman $A$, Lindbald $A K$, Gustavsson $M$, Ring $L$. Factor associated with reflection among students after an advanced pharmacy practice experience (APPE) in Sweden. Am J Pharm Educ. 2009;73(6):107.

20. Wallman A, Lindblad AK, Hall S. A categorization scheme for assessing pharmacy students' levels of reflection during internship. Am J Pharm Educ. 2008;72(1):5.

21. Pennington $K$, Crewel J, Snedden T, Mulhall M, Ellison N. Ignatian pedagogy: transforming nursing education. Jesuit Higher Education. 2013;2(1):34-40.

22. Austin Z, Gregory PA, Chiu S. Use of reflection-in-action and self-assesment to promote critical thinking among pharmacy student. Am J Pharm Educ. 2008;72(3):48.

23. Fisher RC. The potential for problem-based learning in pharmacy education: A clinical therapeutics course in diabetes. Am J Pharm Educ. 1994;58(2):183-9.

24. Gallimore CE, Thorpe JM, Trapskin K. Simulated medication therapy management activities in a pharmacotherapy laboratory course. Am J Pharm Educ. 2011 75(5):95. Available from: doi: 10.5688/ajpe75595.

25. Mateti UV, Konda SS, Khan MG, Nagappa AN. Need for problem-based learning in clinical pharmacy education in India. IJOPP. 2014;7(3):10-3. Available from doi:10.5530/ijopp.7.3.3.s

Article History: Submission Date : 24-01-2018 ; Revised Date : 10-02-2018; Acceptance Date : 14-05-2018.

Cite this article: Hartayu TS. Problem Based Learning in Reflective Pedagogy Paradigm: Innovative Learning in Pharmaceutical Care. J Young Pharm. 2018;10(2)Suppl:s1-s5. 